\title{
The Strategies in Translating English Metaphors into Thai: A Case Study of the American Novel Percy Jackson
}

\author{
Rachadaporn Mata \\ Language Institute \\ Thammasat University, Thailand \\ Supong Tangkiengsirisin \\ Language Institute \\ Thammasat University, Thailand
}

\begin{abstract}
:
As metaphors are known as comparative language avoiding "like" or "as" in the sentences, they need special treatment in translation. Regarding comparisons, there are two different objectives: they may be known and unknown in the target language. The objectives become a translation problem according to different languages, cultures, attitudes and other aspects. This study aimed to investigate the translation techniques used for transferring live metaphors found in a novel into Thai, namely, Percy Jackson \& the Olympians: The Lightning Thief (2005) and its translated version. The translation strategies were studied and analyzed. The analysis relied on the model of Newmark (1988) which proposed seven techniques for metaphor translation. The results of this research showed that the most frequently technique employed was the source metaphor that can be reproduced as the same image in target language, with a total of fifty-seven sentences out of one hundred thirty-six sentences. Additionally, there were also three techniques that were often applied: the metaphor can be translated as a simile by adding some meaning or translating a metaphor as a metaphor and plus some meaning or explanation and the metaphor can be deleted when it is redundant. It can be inferred that to maintain the native sense of language and prevent reader's confusion, the translator provided the equivalent or same image in the target language. Therefore, the author avoided deleting the source image and instead converted it to literal language.
\end{abstract}

Keywords: live metaphor, metaphor, source language, source text, target text, translation, translation strategy

Cite as: Mata, R., \& Tangkiengsirisin, S. (2018). The Strategies in Translating English Metaphors into Thai: A Case Study of the American Novel Percy Jackson. Arab World English Journal for Translation \& Literary Studies, 2 (2).

DOI: http://dx.doi.org/10.24093/awejtls/vol2no2.12 